\title{
Dementia and legal determination of capacity
}

\author{
Demência e avaliação de interdição judicial \\ Valeska Maria Eboli Bello Delineau', Rodrigo Rizek Schultz ${ }^{1}$
}

\begin{abstract}
One of the consequences of dementia is the possibility of a guardianship proceeding that will deprive patients of legal capacity in taking decisions and managing their own assets. Objective: To assess the legal capacity and guardianship proceedings in patients diagnosed with dementia. Methods: Ninety-seven patients diagnosed with dementia and seen at a tertiary hospital were evaluated. Results: Of these 97 patients, 60 (62\%) were female. The mean age of the patients was 77.9 years; average schooling was 5.5 years. The main diagnosis was Alzheimer's disease (73\%): 16 patients were at a mild stage, eight at a moderate stage and 73 at an advanced stage of dementia. Only 28 patients had been legally declared incapable. Conclusion: The large numbers of patients at an advanced stage of dementia, and the relatively few patients legally declared incapable show that legal issues in dementia are problematic.
\end{abstract}

Keywords: legal interdiction; dementia; Alzheimer's disease; prevalence.

\section{RESUMO}

Uma das consequências das demências é a possibilidade da interdição judicial do paciente, retirando-lhe a capacidade jurídica da prática de decisões e administração de bens. Objetivo: Avaliar a existência de capacidade jurídica e da interdição judicial em pacientes com diagnóstico de demência. Métodos: Foram entrevistados 97 pacientes com diagnóstico prévio de demência atendidos no ambulatório de neurologia do comportamento de um hospital terciário. Resultados: Dos 97 pacientes, 60 (62\%) eram mulheres. A média de idade dos pacientes foi de 77,9 anos, e de escolaridade foi de 5,5 anos. O principal diagnóstico foi de doença de Alzheimer: 16 estavam em estágio leve, 8 em estágio moderado e 73 em estágio avançado da demência. Somente 28 pacientes apresentavam interdição judicial. Conclusão: 0 elevado número de pacientes em estágio avançado de demência e reduzido número de pacientes com interdição indicou dificuldades em relação às questões legais da demência.

Palavras-chave: interdição legal; demência; doença de Alzheimer; prevalência.

While normal aging has been associated with the impairment of executive functions, it has been found that the prevalence of impaired decision-making increases significantly in a wide range of neurological disorders commonly seen in the elderly, and that this is seen particularly in the dementias ${ }^{1,2,3}$.

Impaired functional capacity - above all in decisionmaking - gives rise to ethical and legal questions that may have legal consequences. One of these situations is the possibility of a guardianship proceeding for dementia patients, depriving them of legal capacity in taking decisions and managing their own assets. In Brazil, the judicial determination of incapacity is a legal institution laid down in the legislation ${ }^{4}$.

\section{The guardianship proceeding}

Four thematic categories appear consistently in descriptions: 1) professional, including palliative, care; 2) end-of-life issues including euthanasia; 3 ) issues concerning decision-making and the judgment of a substitute when the patient is incapable; and (4) decisions concerning clinical treatments ${ }^{5}$.

For decision-making capacity, it is important to clarify what form the legal procedure of declaring a patient incapable will take. According to the legislation, guardianship proceedings the declaration of incapacity — are a judicial measure by means of which an authority deprives an individual who is of age - in other words over eighteen - of the right to manage his or her own affairs and engage in the activities of civil life. This measure presupposes that the individual is incapable ${ }^{6}$. The declaration of incapacity involves the appointment of a guardian who administers the individual's life and the affairs(s) he is unable to manage by him or herself. The guardian is responsible for carrying out all those civil acts that embody the conservatee's rights ${ }^{6}$.

However, capacity is a state that is as difficult to define as it is to assess. A working definition of capacity might be: what is minimally necessary for an individual to be able to maintain personal decision-making ability ${ }^{7}$. Capacity, legally defined,

\footnotetext{
1 Universidade Federal de São Paulo, Escola Paulista de Medicina, Setor de Neurologia do Comportamento, Departamento de Neurologia e Neurocirurgia, São Paulo SP, Brasil.

Correspondence: Valeska Maria Eboli Bello Delineau; Departamento de Neurologia e Neurocirurgia da UNIFESP; Rua Pedro de Toledo, 650; 04023-900 São Paulo SP, Brasil; E-mail: mari.eboli@yahoo.com.br 
is the ability to acquire rights and take on duties. Article 1 of the Brazilian Civil Code lays down that every person is capable of rights and duties within the civil order ${ }^{8}$. Legal incapacity is, therefore, a restriction or constraint upon civil acts. The concept of legal capacity differs from the medical concept of capacity, which defines a set of skills required such as memory, judgment and decision-making, in order to manage affairs and carry out daily tasks ${ }^{9}$. Mental capacity is not universal. Absence of the capacity in a given situation may not imply its existence in other situations; it may therefore change ${ }^{10}$.

The legal entity of incapacity aims principally to protect individuals who are significantly impaired, from a legal standpoint, and the forms of protection are graded ${ }^{11}$. Guardianship proceedings ( "interdiction" in Brazilian legal parlance) are regulated by the Code of Civil Procedure ${ }^{12}$.

The aims of the present study were to: (i) evaluate the prevalence of guardianship actions in patients diagnosed with dementia in a neurological outpatient clinic; (ii) evaluate in which period of Alzheimer's disease $(\mathrm{AD})$ the interdiction of the patient was determined and any difficulties in obtaining guardianship; (iii) in the case of absence of the guardianship, to evaluate how families resolve the legal problems in practice.

\section{METHODS}

\section{Participants}

In a six-month period, 97 patients were recruited from an outpatient clinic at the Behavioral Neurology Section. All patients met Diagnostic and Statistical Manual of Mental DisordersDSM-IV diagnostic criteria for dementia ${ }^{13}$. The clinical diagnosis was arrived at in accordance with published criteria: The National Institute of Neurological Communicative Disorders and Stroke-Alzheimer's Disease and Related Disorders criteria for Alzheimer's disease ${ }^{14}$; the National Institute of Neurological Disorders and Stroke-Association Internationale pour la Recherche et L'Enseignement en Neurosciences criteria for vascular dementia ${ }^{15}$; and the revised diagnostic criteria for the behavioral variant of frontotemporal dementia (bvFTD) ${ }^{16}$. On all occasions, a written explanation of the research design was read by the principal researcher or the primary family caregivers for the patient, and additional explanations were given when necessary, after which an informed consent form was signed. All proceedings were approved by the Institutional Review Board.

After patients and their caregivers consented to participate in this study, by signing an informed consent form approved by the local ethics committee, the objectives of the study were presented to them.

The inclusion criteria for assessing the patients were: prior determination of a diagnosis of dementia; pre-established Clinical Dementia Rating Scale (CDR) ${ }^{17}$; Mini-mental State Examination (MMSE) ${ }^{18}$ and/or severe Mini-mental State Examination (SMMSE) ${ }^{19}$ and the presence of the caretaker on the date of application for the attached protocol.

\section{Instruments \\ Clinical examination and neuropsychological evaluation}

The aim was to study patients with mild dementia who had a CDR score of 1 , patients with moderate dementia with a CDR score of 2 and patients with severe dementia with a CDR score of $3^{17}$. For this study, we used a Brazilian version of the MMSE and a Brazilian version of the SMMSE with cutoffs according to education level ${ }^{18,19}$. The protocol was performed individually by the same investigator (V.M.E.B.D.).

The following data were collected for all study participants: gender, age and schooling. Caretakers were also interviewed as to their degree of kinship to the patient and whether the patient had already been submitted to a legal capacity determination or some other legal procedure.

Ninety-seven patients were enrolled (Table 1).

The group was subdivided into three levels of severity: 16 (16.49\%) with CDR 1; 8 (8.24\%) with CDR 2 and 73 (75.25\%) with CDR 3. We thus found that $81(83.5 \%)$ patients were at a moderate or severe stage (CDR 2 and CDR 3).

Alzheimer's disease was the diagnosis in 71 patients, accounting for $73 \%$ of all individuals assessed. The second most-frequent diagnosis was bvFTD with eight patients. We also found six (6\%) patients with mixed dementia, four (4\%) with vascular dementia and eight (8\%) patients with other types of dementia.

\section{Data analysis}

A descriptive analysis was employed for all subjects in regard to gender, age at examination, schooling, CDR, MMSE and SMMSE scores. The threshold of significance was set at $\mathrm{p}<0.05$.

The continuous and semi-continuous data for the variables were compared with the Gauss curve and determined as parametric by means of the Kolmogorov-Smirnov test and Shapiro-Wilk test; the data were therefore represented by mean and standard deviation of the sample. The Student's $\mathrm{t}$ test for independent samples was used to compare two independent groups ${ }^{20}$.

Categorical data were represented by absolute (n) and relative (\%) frequency, and Pearson's chi-squared test was used to analyze contingency matrices ${ }^{20}$.

For the entire study, the risk of committing a type I error was considered to be less than or equal to $5 \%$ and the beta risk for committing a type II error was less than or equal to $20 \%^{20}$.

Table 1. Demographic characteristics of dementia patients.

\begin{tabular}{lccc}
\hline \multirow{2}{*}{ Demographic data } & \multicolumn{3}{c}{ Individuals $\mathrm{n}=97$} \\
\cline { 2 - 4 } & $\mathrm{n}(\%)$ & mean [SD] & Range \\
\hline Sex & $37(38)$ & & \\
Male & $60(62)$ & & \\
Female & & $77.9[8.4]$ & $57-95$ \\
Age (years) & $5.5[4.4]$ & $0-15$ \\
\hline Schooling (years) & & & \\
\hline SD: standard deviation. & & &
\end{tabular}




\section{RESULTS}

We found that of the 97 patients analyzed, 28 (29\%) had undergone guardianship proceedings and 16 (16.49\%) had been under some other form of legal representation. The remaining $53(54.63 \%)$ patients did not fall into either category of judicial representation.

We observed that $59(60.8 \%)$ of the caregivers were the children of the patients analyzed, 32 (32.9\%) were their spouses, four (4.1\%) were second-degree relations, one (1\%) was a sibling and one (1\%) was a friend.

We found that after guardianship proceedings, 12 children became caregivers, making up $43 \%$ of the individuals assessed. In most cases-15 patients (54\%) - guardianship was exercised by the spouse. Only one patient's caregiver was a second-degree relation.

\section{Relationship between patients under guardianship and patients not under guardianship}

The mean age was $79.01 \pm 8.13$ years of age for non-assessed patients and $75.24 \pm 8.74$ years of age for legally assessed patients; further demographic data follows below (Table 2).

CDR: only one of the conservatees (3.57\%) had CDR 1, two (7.14\%) had CDR 2, and 25 (89.28\%) had CDR 3. For individuals not under guardianship, 15 (21.73\%) had CDR 1, six (8.69\%) had CDR 2, and 48 (69.56\%) had CDR 3 (Figure 1).

In terms of an etiological diagnosis of dementia, we found that for $\mathrm{AD}$, out of a total of 71 patients, 56 individuals were not under guardianship (81.15\%) and only 15 individuals (53.57\%) were under guardianship $(\mathrm{p}=0.006)$. For bvFTD, only two $(2.89 \%)$ patients were not under guardianship, while six (21.43\%) individuals were under guardianship $(\mathrm{p}=0.003)$. For mixed dementia,

Table 2. Demographic and clinical characteristics of assessed and non-assessed patients.

\begin{tabular}{|c|c|c|c|c|}
\hline \multirow{2}{*}{ Variable } & \multicolumn{2}{|c|}{$\begin{array}{l}\text { Under guardianship } \\
\qquad(\mathrm{n}=28)\end{array}$} & \multicolumn{2}{|c|}{$\begin{array}{l}\text { Not under guardianship } \\
\qquad(\mathrm{n}=69)\end{array}$} \\
\hline & $\mathrm{n}$ & $\begin{array}{l}\text { mean } \\
{[S D]}\end{array}$ & $\mathrm{n}$ & $\begin{array}{l}\text { mean } \\
{[S D]}\end{array}$ \\
\hline \multicolumn{5}{|c|}{ Demographic data } \\
\hline Age & & $\begin{array}{l}75.24 \\
{[8.74]}\end{array}$ & & $\begin{array}{l}79.01 \\
{[8.13]}\end{array}$ \\
\hline Schooling & & $\begin{array}{c}5.75 \\
{[3.56]}\end{array}$ & & $\begin{array}{l}5.43 \\
{[4.73]}\end{array}$ \\
\hline \multicolumn{5}{|l|}{ Sex } \\
\hline Male & $17(61 \%)$ & & $20(29 \%)$ & \\
\hline Female & $11(39 \%)$ & & $49(71 \%)$ & \\
\hline \multicolumn{5}{|l|}{ Clinical data } \\
\hline \multicolumn{5}{|l|}{ CDR } \\
\hline 1.0 & $1(3.57 \%)$ & & $15(21.73 \%)$ & \\
\hline 2.0 & $2(7.14 \%)$ & & $6(8.69 \%)$ & \\
\hline 3.0 & $25(89.28 \%)$ & & $48(69.56 \%)$ & \\
\hline $\begin{array}{l}\text { MMSE } \\
\text { (CDR } 1 \text { and 2) }\end{array}$ & & $\begin{array}{c}15 \\
{[10]}\end{array}$ & & $\begin{array}{l}20.19 \\
{[6.41]}\end{array}$ \\
\hline SMMSE (CDR 3) & & $\begin{array}{c}7.36 \\
{[9.25]}\end{array}$ & & $\begin{array}{c}8.64 \\
{[9.01]}\end{array}$ \\
\hline
\end{tabular}

SD:standard deviation;CDR:Clinical Dementia RatingScale;MMSE:Mini-mental State Examination; SMMSE: severe Mini-mental State Examination. only three (4.34\%) patients were not under guardianship, while three $(10.71 \%)$ individuals were under guardianship. For vascular dementia, only three (4.34\%) patients were not under guardianship, while one (3.57\%) individual was under guardianship. Furthermore, we observed that three (10.71\%) individuals under guardianship had other dementias (Figure 2).

\section{DISCUSSION}

We did not find significant differences between the comparative results of individuals under guardianship and patients not under guardianship for age and schooling.

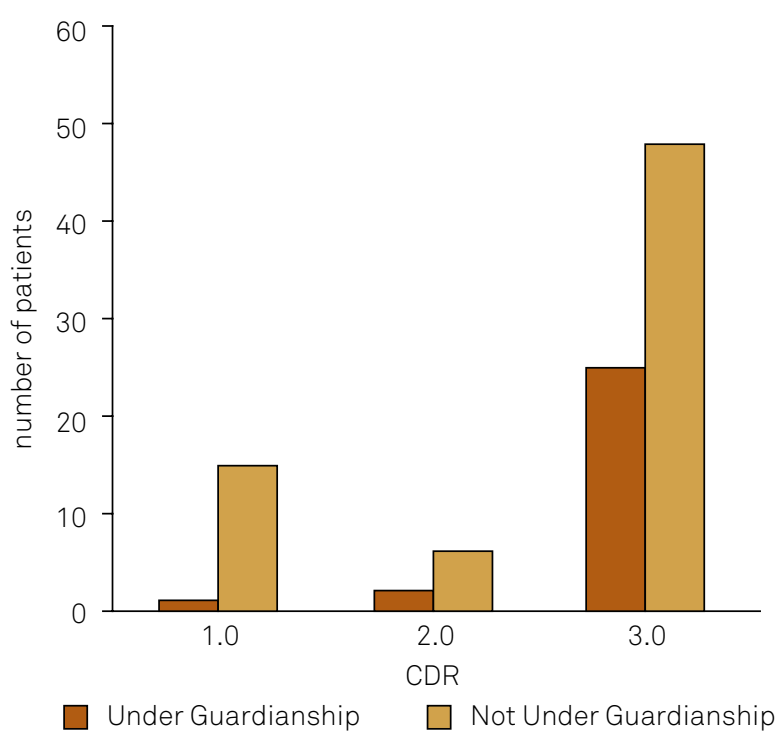

CDR: Clinical Dementia Rating Scale

Figure 1. Ratio between individuals under guardianship and not under guardianship by severity of dementia.

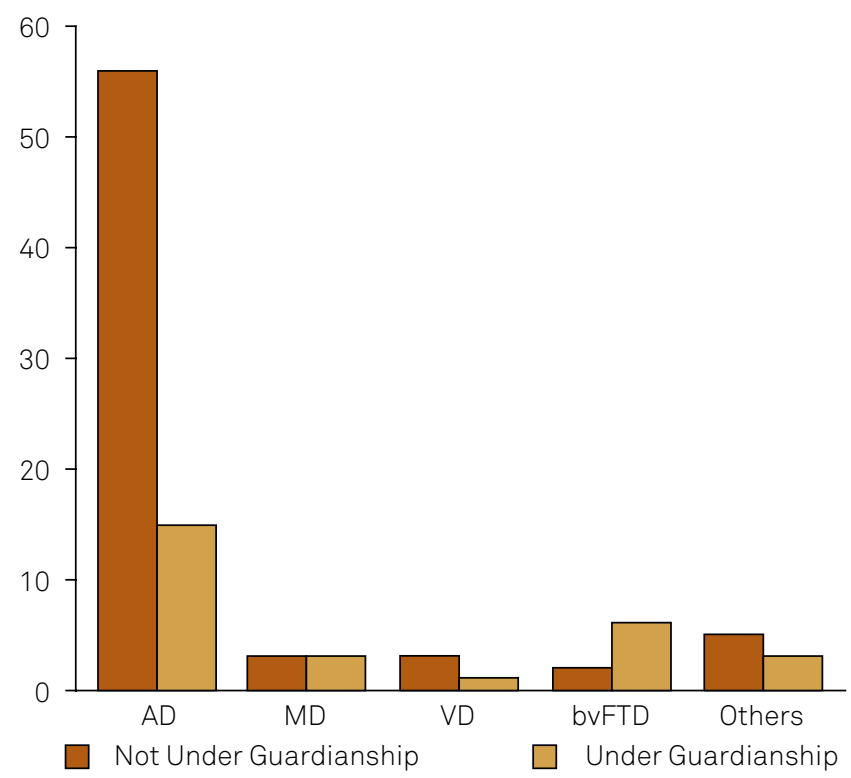

AD: Alzheimer's disease; MD: mixed dementia;VD: vascular dementia; bVFTD: behavioral variant of frontotemporal dementia.

Figure 2. Diagnosis of dementia by individuals under guardianship and not under guardianship. 
However, although the total population studied is predominantly in the moderate or severe stage of dementia (83.5\%), we observed that only 44 (45.37\%) of the patients were under some form of judicial representation; in other words, many patients not in the initial stage of the disease were not under any form of legal protection. There may be several reasons underlying this state of affairs. In answers given by caregivers during application of the study protocol, many claimed there was insufficient personal equity to warrant a petition for guardianship or representation, while others claimed that the high cost of the legal process militated against the procedure. We also perceived a lack of information about the need for guardianship, since most stated they were unaware of the procedure. We should consider whether there is a cultural hurdle in Brazil to the discussion and assessment of judicial guardianship procedures, since some families with strong religious beliefs find it hard to address issues of the end of life and its legal consequences.

Another important difference relates to gender. Whereas in the total population there are more female patients, only 11 were under guardianship. This may be a cultural difference. The population in the present study is predominantly women who are not committed to a bread-winning role or to the family's financial decisions. Men have mainly been responsible for financial administration and for managing the family's equity, and if they are incapable of doing so, this would lead the caregivers to take steps to find a legal solution. We may expect that, in the future, the increasingly-important role of women in the workplace will alter this scenario.

A significant analysis of the diagnosis needs to be produced. While there was a predominance of $\mathrm{AD}$ in the total population (73\%), this fell to $54 \%$ in individuals who were under guardianship. For bvFTD, this was only $8 \%$ in the total population, but among individuals under guardianship it was $21 \%$. We need to investigate how far the prominent clinical picture in the behavioral scope of bvFTD directly impacts the decisions taken by the families involved and in the decisions of the judges, given that a more discreet clinical presentation of $\mathrm{AD}$ - even with apathy - may not strike those involved in guardianship proceedings so forcefully.

There is a significant difference between the main caregiver identified in a medical appointment and the legally-appointed caregiver. Whereas in the general population, $60.82 \%$ of caregivers are the children, they account for only $43 \%$ of caregivers in the case of conservatees. In most patients (54\%), guardianship was exercised by the spouse. We may stress here that although it is actually the children who take care of dementia patients, the law still finds it safer to pass administrative and financial responsibility to the other spouse. In most cases the latter is the main beneficiary of the will, because before 1977, the legal regime for assets in the marriage was universal community of assets, where all the assets acquired before and after the marriage were shared equally between the couple. Given that the patients assessed are elderly, we may deduce that most of the marriages are ruled under the aegis of the law that pertained up until 1977, which may lead judges to decide for guardianship in most cases by the capable spouse.

Studies have shown that ethical and legal discussions of decisions taken in the end-of-life and dementia settings vary by local culture and religious influences. Thus, in strongly Catholic countries such as Spain and Italy, there is greater resistance to engaging in discussions on the end of life and its consequences than in countries less influenced by religion such as Belgium and Norway ${ }^{21}$.

In a similar Italian study with patients diagnosed with dementia, 172 individuals were assessed at the outset of the study, three of whom had been legally declared incapable before the study began. Of the remaining 169, guardianship was denied in 91 (53.8\%). Of the remaining 78 (46.2\%) patients, 55 were declared incapable and 23 were still awaiting the sentence. In this study, the result was that there was a small number of patients found requiring guardianship: $58(34 \%)$ patients. This figure is slightly higher than that found in our own study $(28 \%)^{22}$. The Italian study makes for an interesting comparison since Brazil is culturally very similar to Italy.

We conclude that the rate of legal guardianship proceedings in the case of patients obviously impaired by dementia is lower than expected.

The assessment of an individual's competency or capacity is a task of enormous responsibility, going beyond a merely clinical analysis. A multidisciplinary team must therefore carry out a thorough evaluation. To declare someone incapable, even if only for specific tasks, means depriving that person of fundamental rights and freedoms and causes a drastic change in the individual's life ${ }^{23}$.

Few studies currently address the legal issues involved in dementias, but this discussion will grow alongside the increased incidence of the disease, which leads us to reflect on the need for greater involvement of a multidisciplinary team, the family, and society itself in these aspects.

\section{References}

1. Caixeta L, Costa JNL, Vilela ACM, Nóbrega M. The development of the dementia concept in $19^{\text {th }}$ century. Arq. Neuropsiquiatr. 2014;72(7):564-7. https://doi.org/10.1590/0004-282X20140069

Almeida OP. Instrumentos para avaliação de pacientes com demência. Rev.Psiquiatr Clin (Santiago). 1999;26(2):78-89.

3. Sahadevan S, Chin JJ, Yap MN, Yeoh OE. Assessing decision-making capacity in dementia patients: a semi-structured approach. Ann Acad Med Singapure. 2003;32(6):749-55.
4. Barbas NR, Wilde EA. Competency issues in dementia: medical decision making, driving and independent living. J Geriatr Psychiatry Neurol. 2001;14(4):199-212. https://doi.org/10.1177/089198870101400405

5. Woods B, Pratt R. Awareness in dementia: ethical and legal issues inrelation to people with dementia. Aging Ment Health. 2005;9(5):423-9. https://doi.org/10.1080/13607860500143125 
6. Menezes JB, Correia Neto JF. Interdição e curatela no novo CPC à luz da dignidade da pessoa humana e do direito civil constitucional. 2014 [cited 2015 oct 30]. Available from: http://www.publicadireito. com.br/artigos/?cod $=029$ b50 deea7a25c4

7. Moye J, Marson DC, Edelstein B. Assessment of capacity in an aging society. Am Psychol. 2013;68(3):158-71. https://doi.org/10.1037/a0032159

8. Brasil. Lei n 10.406, de 10 de janeiro de 2002. Insitui o Código Civil. Diário Oficial União. 11 jan 2002.

9. Arias JJ.A time to step in: legal mechanisms for protecting those with declining capacity. Am J Law Med. 2013;39(1):134-59. https://doi.org/10.1177/009885881303900103

10. Fernandes L. [Ethical and legal issues in late stage of dementia]. Acta Med Port. 2008;21(1):65-72. Portuguese.

11. Diniz MH. Curso de direito civil brasileiro. 28a ed. São Paulo: Saraiva; 2011. Chapter 20: Pessoa natural; p. 162-219.

12. Brasil. Lei No 13.105 de 16 de marco de 2015. Código de Processo Civil. in: Diário Oficial União. 17 mar 2015.

13. American Psychiatric Association. Diagnostic and statistical manual of mental disorders. 4th ed. Washington, DC: American Psychiatric Association; 1994.

14. McKhann G, Drachman D, Folstein M, Katzman R, Price D, Stadlan EM. Clinical diagnosis of Alzheimer's disease: report of the NINCDS-ADRDA Work Group under the auspices of Department of Health and Human Services Task Force on Alzheimer's Disease. Neurology.1984;34(7):939-44. https://doi.org/10.1212/WNL.34.7.939

15. Román GC, Tatemichi TK, Erkinjuntti T, Cummings JL, Masdeu JC, Garcia JH et al. Vascular dementia: diagnostic criteria for research studies. Report of the NINDS-AIREN International Workshop. Neurology.1993;43(2):250-60. https://doi.org/10.1212/WNL.43.2.250
16. Rascovsky K, Hodges JR, Knopman D, Mendez MF, Kramer JH, Neuhaus $J$ et al. Sensitivity of revised diagnostic criteria for the behavioural variant of frontotemporal dementia. Brain. 2011;134(9):2456-77. https://doi.org/10.1093/brain/awr179

17. Hughes CP, Berg L, Danziger WL, Coben LA, Martin RL. A new clinical scale for the staging of dementia. Br J Psychiatry.1982;140(6):566-72. https://doi.org/10.1192/bjp.140.6.566

18. Bertolucci PHF, Brucki SMD, Campacci SR, Juliano YO. Mini-exame do estado mental em uma população geral: impacto da escolaridade. Arq Neuropsiquiatr.1994;52(1):1-7. https://doi.org/10.1590/S0004-282X1994000100001

19. Wajman JR, Oliveira FF, Schultz RR, Marin SMC, Bertolucci PHF. Educational bias in the assessment of severe dementia: Brazilian cutoffs for severe Mini-Mental State Examination. Arq Neuropsiquiatr. 2014;72(4):273-7. http://dx.doi.org/10.1590/0004-282X20140002

20. Rosner B. Fundamentals of biostatistics. 2nd ed. Boston: PWS Publishers; 1986.

21. Evans N, Pasman HR, Veja Alonso T, Van den Block L, Miccinesi G, Van Casteren V et al. End-of-life decisions: a cross-national study of treatment preference discussions and surrogate decision-maker appointments. PLoS One. 2013;8(3):e57965. https://doi.org/10.1371/journal.pone.0057965

22. Gainotti S, Fusari Imperatori S, Spila-Alegiani S, Maggiore L, Galeotti F, Vanacore L et al. How are the interests of incapacitated research participants protected through legislation? An Italian study on legal agency for dementia patients. PLoS One. 2010;5(6):e11150. https://doi.org/10.1371/journal.pone.0011150.

23. Álvaro LC. [Competency: general principles and applicability in dementia]. Neurology. 2012;27(5):290-300. Spanish. https://doi.org/10.1016/j.nrl.2011.12.005 